\title{
Spatial Distribution of Venturia inaequalis Airborne Ascospores in Orchards
}

\author{
J. Charest, M. Dewdney, T. Paulitz, V. Philion, and O. Carisse
}

First, second, and third authors: Department of Plant Science, McGill University, 21,111 Lakeshore Road, Sainte-Anne de Bellevue, Quebec, Canada; H9X 3V9; fourth author: IRDA, Sainte-Hyacinthe, Quebec, Canada, J2S 7B8; and fifth author: Agriculture and AgriFood Canada, Horticultural Research Centre, 430 Gouin Blvd., Saint-Jean-sur-Richelieu, Québec, Canada, J3B 3E6.

Current address of J. Charest: MAPAQ, Direction Régionale de la Montérégie, 491-2, rue Sainte-Marie, Marieville, Quebec, Canada, J3M 1M4.

Current address of T. Paulitz: U.S. Department of Agriculture-Agricultural Research Service, Root Disease and Biological Control Research

Unit, 363 Johnson Hall, Washington State University, Pullman 99164.

Accepted for publication 22 March 2002.

\section{ABSTRACT}

Charest, J., Dewdney, M., Paulitz, T., Philion, V., and Carisse, O. 2002. Spatial distribution of Venturia inaequalis airborne ascospores in orchards. Phytopathology 92:769-779.

Apple scab (Venturia inaequalis) causes important economic losses in many apple production areas of the world. The disease is controlled by numerous fungicide applications regardless of the presence of ascospores in the orchard. Airborne ascospore concentration (AAC) can be measured in real time to time fungicide applications. However, the level of heterogeneity of the AAC in commercial orchards was unknown. Consequently, the spatial distribution of $V$. inaequalis ascospores was studied in a commercial apple orchard of 0.43 ha. The potential ascospore dose (PAD) and $\mathrm{AAC}$ were measured in 40 quadrats each of $108 \mathrm{~m}^{2}$. In each quadrat, the AAC was monitored during the major rain events in spring 1999 and 2000 using spore samplers. The variance-to-mean ratio for the PAD and for most of the AAC sampling dates was $>1$, indicating an aggregated pattern of distribution. None of the frequency distributions of the most important ascospore ejection events followed the Poisson probability distribution, indicating that the pattern of distribution was not random. For all events, AAC had an aggregated pattern of distribution as suggested by the negative binomial distribution. The PAD followed neither the Poisson nor the negative binomial distribution. Geostatistical analyses confirmed the aggregated pattern of distribution. The cultivars had an effect on the PAD and AAC distribution pattern, but both PAD and AAC were not uniformly distributed within a block of the same cultivar. Therefore, the number, location, and height of samplers required to estimate AAC in orchards need to be investigated before using information on AAC for decision making.

Additional keywords: aerobiology, disease management, geostastical analysis, spore trapping.
Apple scab, caused by Venturia inaequalis (Cooke) G. Wint., is a major disease of apple trees. The disease causes important economic losses in the rainfed agricultural areas of the world, where control is necessary for commercial apple production. $V$. inaequalis is an ascomycete that overwinters as immature pseudothecia in apple leaf debris. In the spring, ascospores develop in these pseudothecia and are actively discharged during rain. The ascospores are carried by the wind to susceptible young leaves and fruit, where they cause primary infections leading to lesions and production of conidia. The conidia are responsible for the secondary infections and epidemic build-up (20).

Most control strategies are oriented toward elimination of the primary infections to avoid epidemic build up caused by secondary cycles. In the northeastern United States and eastern Canada, the primary infections can occur from bud break to early June, when the limited stock of ascospores in the pseudothecia is depleted (15). Models of ascospore maturation in the spring have been developed $(15,33)$. These models, based on degree-day accumulation, could be used to predict the beginning and the end of the ascospore ejection season. However, they tend to be regionally based and generally are not accurate enough to provide the time at which the first and the last fungicide applications should be done. Fungicide timing is seldom based on inoculum assessment $(6,25-$ 27). The potential ascospore dose (PAD) is a useful tool for pre-

Corresponding author: O. Carisse; E-mail address: carisseo@em.agr.ca

Publication no. P-2002-0507-01R

(c) 2002 The American Phytopathological Society dicting the total amount of inoculum in an orchard and has been shown to effectively improve apple scab management (26). However, limitations such as the time required for the fall scab assessment, requirement for trained personnel, and the potential lack of accuracy may explain the limited use of the PAD by growers (25). An alternative to PAD measurement would be to measure airborne ascospore concentration (AAC) directly in the orchard (30). Recently, it has been shown that volumetric spore samplers can be used as a tool for ascospore assessment $(3,12)$. Furthermore, Aylor (6) and Aylor and Kiyomoto (8) showed that the number of primary apple scab lesions is quantitatively related to the airborne ascospore concentration.

The use of volumetric spore samplers in apple scab management is based on the hypothesis that the AAC is uniformly distributed in commercial apple orchards. Ideally, spore samplers would be placed in an area where the AAC is representative of the whole orchard. Aylor (5), Aylor and Anagnostakis (7), and Aylor and Sutton (9) studied aerial concentration of ascospores in an apple orchard and showed that there was a rapid decrease in the concentration of ascospores with increasing height above the ground. The important vertical variation of AAC was explained by a rapid change in wind speed and turbulent diffusivity near the ground $(1,2)$. Aylor $(6)$ also developed models of spore dispersal. These models estimate spore concentration and spore deposition but are restricted to points along the centerline of the orchard in the direction of the wind. Therefore, they do not account for diffusion in the crosswind direction (6). These models are very useful for theoretical studies and modeling but they are too sophisticated to be useful from a practical point of view. 
Spatial pattern analyses in plant disease epidemiology were reviewed by Campbell and Madden (11). Spatial patterns of disease dispersal result from the interaction between physical, biological, and environmental factors (23). Statistical methods defining spatial patterns of disease are used to understand the specific factors responsible for the distribution patterns. For the quadrat-based analysis, mapping, evaluation of goodness-of-fit of discrete distribution to frequency count data, indexes of dispersion calculation, calculations of variances of blocked quadrats, and the determination of the degree of spatial autocorrelation among quadrats are the main tests of spatial pattern analysis (11). Poisson and negative binomial probability distributions often are used to test the frequency distribution of the quadrat counts. They indicate whether a spatial pattern of disease is random or aggregated, respectively (11).

These tests of spatial pattern analysis do not consider the physical location of the quadrat or its relationship with other sample sites in their calculations. More recently, geostatistical analyses have been considered as a more powerful and quantitative method that takes into account spatial relationships in the

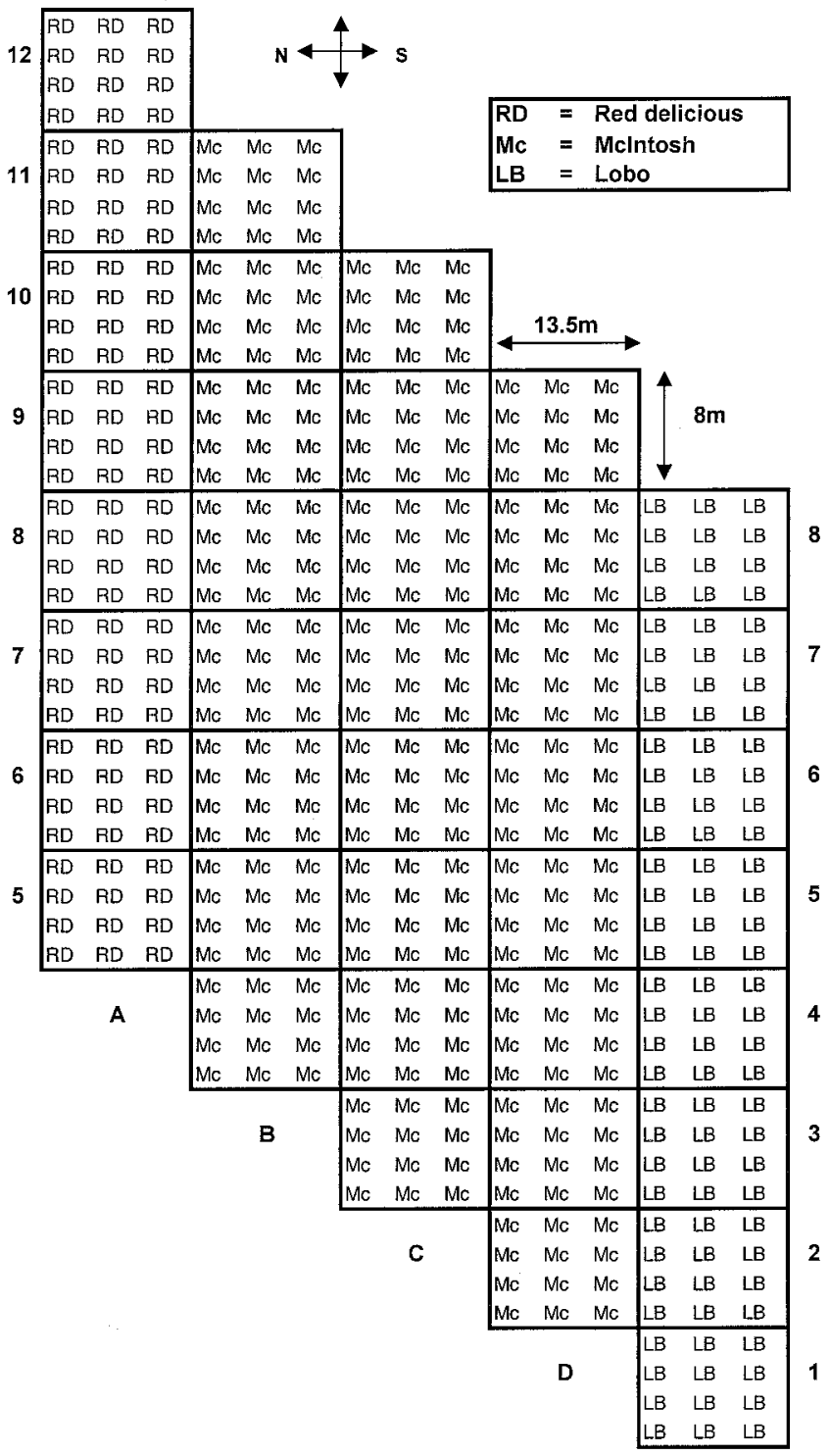

$\mathbf{E}$

Fig. 1. Description of the commercial apple orchard located in Dunham, Quebec, Canada. RD = Red Delicious trees, $\mathrm{Mc}=$ McIntosh trees, and LB = Lobo trees. The tree spacing was 4.5 by $2 \mathrm{~m}$. analysis $(31,34)$. Geostatistics are based on the principle of regionalized variables, meaning variables that have a spatial distribution (23). Geostatistical techniques take into account both the randomness and the structured characteristics of the regionalized variables (19). By quantification of the spatial dependence, semivariograms can be used to describe the spatial correlation structure (19). Semivariograms measure the variation among samples separated by the same distance. The quantitative representation of the spatial variation of the inoculum within the orchard should allow the description of the spatial pattern of the disease.

The first objective of this research was to identify the pattern of spatial distribution of the primary inoculum of $V$. inaequalis in a commercial apple orchard. The second objective was to quantify the level of spatial dependence between quadrats for PAD and AAC. The third objective was to correlate the distribution of PAD and the distribution of AAC in order to evaluate the possibility of using PAD as a prediction method for AAC spatial distribution.

\section{MATERIALS AND METHODS}

Orchard site. The experiment was conducted in a well-maintained commercial apple orchard located in Dunham, Quebec, Canada, which was selected for being representative of the Quebec apple orchards. The orchard block was composed of 28 rows of 37 to 45 semi-dwarf trees, grafted onto MM 106 rootstocks and planted in 1988. The tree spacing was $2 \mathrm{~m}$ in the row and $4.5 \mathrm{~m}$ across the row. The block was composed of three cultivars: Red Delicious, McIntosh, and Lobo. An area of 0.43 ha in the middle of the orchard block was split into 40 quadrats of 12 trees ( 4 trees in three rows). The quadrat size was 13.5 by $8 \mathrm{~m}$. Of the quadrates studied, 24 consisted of McIntosh, 8 of Red Delicious, and the remaining 8 of Lobo (Fig. 1).

Inoculum assessment. Two different types of data were collected in order to evaluate the spatial distribution of ascospores: PAD and AAC. The PAD inoculum assessment method estimates the number of ascospores that could be released per square meter of orchard. It is the product of the number of scab lesions per square meter of leaf tissue on terminal shoots just before leaf fall, pseudothecia per lesion, asci per pseudothecium, ascospores per ascus, and the proportion of orchard floor covered by leaf litter at bud break (16). To evaluate the PAD, a fall scab assessment was done on 5 October 1998 and 8 October 1999. In each quadrat, the number of scabbed leaves was counted on eight shoots from each of three trees. The following spring (20 April 1999 and 28 April 2000), an evaluation of the leaf litter density was done in each quadrat using the point-intercept method (28). A 10-m rope with tags spaced every $0.2 \mathrm{~m}$ was stretched diagonally across the middle row and alleys of each quadrat. The presence or absence of apple leaf debris was recorded every $0.2 \mathrm{~m}$. Two measurements of $10 \mathrm{~m}$ were done on an $\mathrm{X}$ crossing the middle of the quadrat where the spore sampler was placed. The leaf litter density was expressed in percentage of orchard floor covered by apple leaf.

The AAC is an estimation of the number of ascospores present per cubic meter of air. During the ascospore release seasons of 1999 and 2000, the AAC was measured using volumetric spore samplers of the Rotorod type $(3,12)$. Spore samplers were placed in the middle of each quadrat at $0.4 \mathrm{~m}$ above the ground (4). They were automatically activated at the beginning of each rain, using leaf wetness sensors and a CR-10 data logger (Campbell Scientific, Edmonton, Canada). The 40 spore samplers operated for a maximum of $6 \mathrm{~h}$ of leaf wetness during the daylight period (5:00 to 22:00). From 5 May to 15 June 1999 and 4 to 26 May 2000, the AAC was monitored for the major rain events during the two seasons of ascospore ejections. The number of ascospores on the entire surface of the rod was counted with a microscope at a magnification of $\times 250$.

Data analysis. All analyses of spatial distribution were conducted separately for the PAD and each of the AAC sampling 
dates and for both years, with the quadrat as the sampling unit. Analyses were conducted with data from all cultivars and with data from cv. McIntosh only. In 1999 and 2000, five and three ascospore ejection events were retained for data analysis, respectively. Data from the three other rain events were not included in the analysis because the number of ascospores trapped was too low to adequately estimate AAC. Values of PAD and AAC were grouped into 10 classes and represented in gray-tone intensity maps. Statistical analyses then were performed to evaluate the spatial pattern of distribution, based on the quadrat data.

Distribution analysis. The first test used was the variance-tomean ratio, which gave an indication of the type of distribution pattern (regular, random, or clustered) of the data. This simple index of dispersion was calculated by dividing the sample variance by the sample mean. When the ratio of $s^{2} / \bar{x}$ is $<1,=1$, or $>1$, the pattern of distribution is considered regular, random, or aggregated, respectively (11). The Poisson probability distribution was used to test whether a given spatial pattern of distribution was random or nonrandom based on classes of inoculum (11).

When the frequency distribution of the ascospore classes corresponded to the expected frequency distribution of Poisson, deter-
TABLE 1. Potential ascospore dose (PAD) and airborne ascospore concentration (AAC) of Venturia inaequalis for apple cvs. Red Delicious, McIntosh, and Lobo in 1999 and 2000 in a commercial orchard located in Dunham, Quebec, Canada

\begin{tabular}{lcccr}
\hline Sampling date & Year & Red Delicious & McIntosh & Lobo \\
\hline PAD $^{\text {a }}$ & 1999 & 255.2 & $8,466.6$ & 402.2 \\
PAD & 2000 & 589.0 & $7,975.7$ & $4,292.0$ \\
AAC & & & & \\
May 5 & 1999 & 1.1 & 7.7 & 2.6 \\
May 8 & 1999 & 6.8 & 11.1 & 5.1 \\
May 24 & 1999 & 1.1 & 6.5 & 2.9 \\
May 26 & 1999 & 1.7 & 1.7 & 1.6 \\
June 6 & 1999 & 2.1 & 3.0 & 2.8 \\
May 6 & 2000 & 0.8 & 2.6 & 0.6 \\
May 7 & 2000 & 0.9 & 0.7 & 0.2 \\
May 9 & 2000 & 0.2 & 0.7 & 0.2 \\
\hline
\end{tabular}

a PAD in ascospores per $\mathrm{m}^{2}=(8$ ascospores/ascus $\times 25$ pseudothecia per lesion $\times 80$ asci per pseudothecium $\times$ average number of lesions per leaf per quadrate $\left./ 0.004 \mathrm{~m}^{2}\right) \times(\%$ leaf litter density $)$.

b AAC in ascospores per $\mathrm{m}^{3}$ averaged over all quadrats.

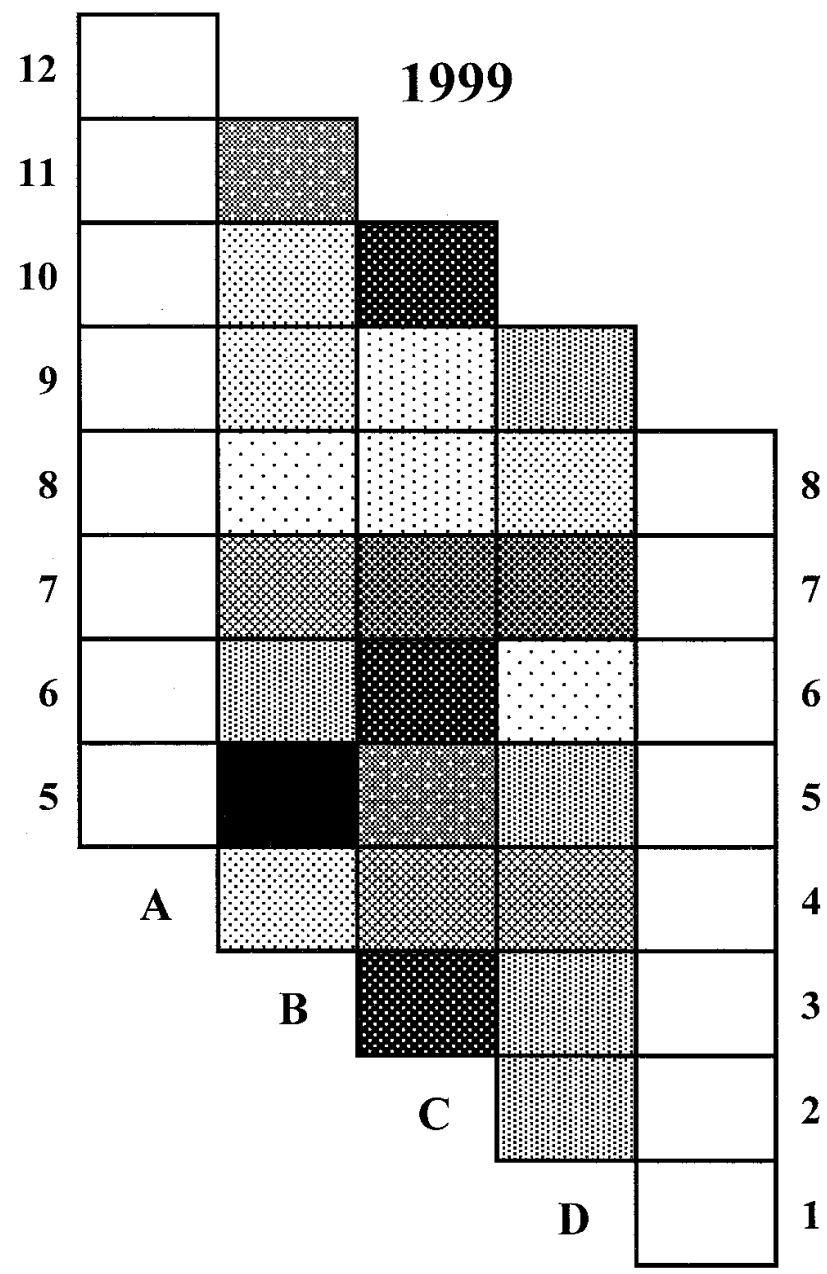

PAD (ascospores $/ \mathbf{m}^{2}$ )

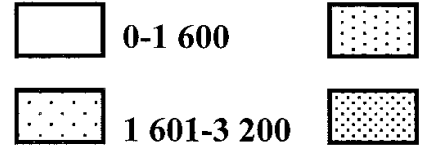

E
8

7

6

5

4

3

2

1
$3201-4800$
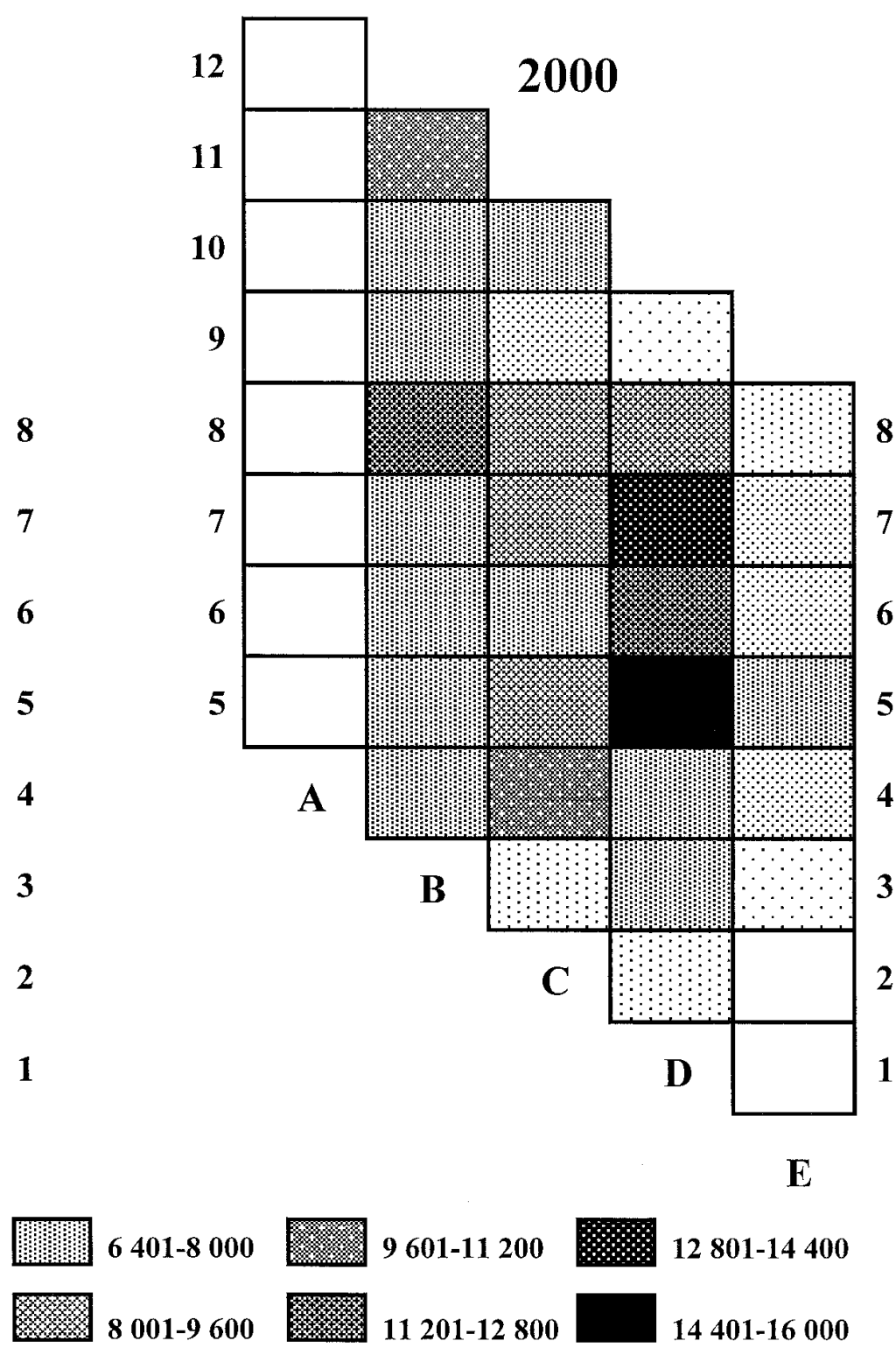

$6401-8000$

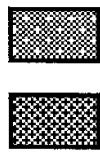

$9601-11200$

$12801-14400$

$8001-9600$

8

7

6

5

4

3

2

Fig. 2. Spatial distribution of the potential ascospore dose (PAD) of Venturia inaequalis measured in 1999 and 2000. 

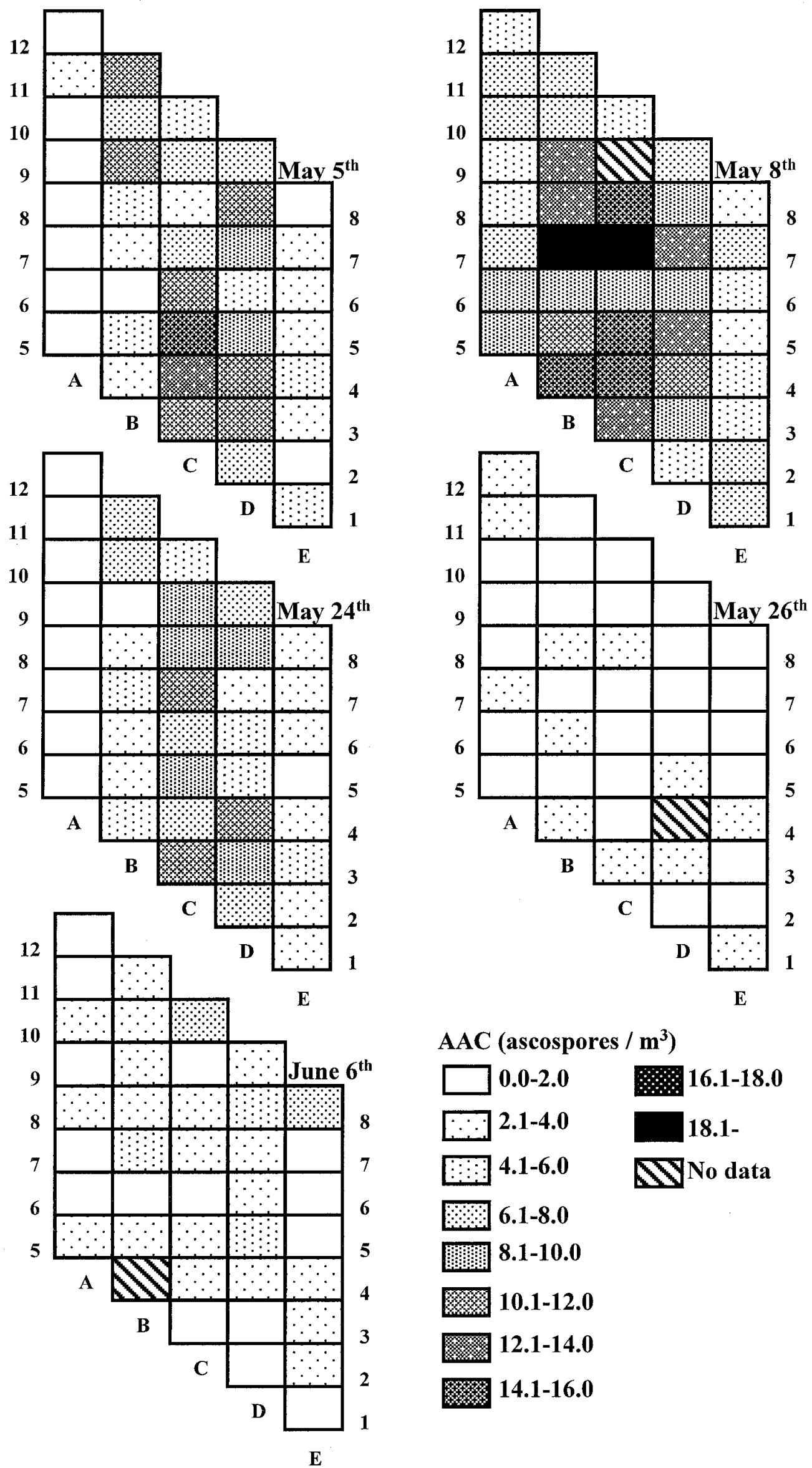

AAC (ascospores / $\mathbf{m}^{3}$ )

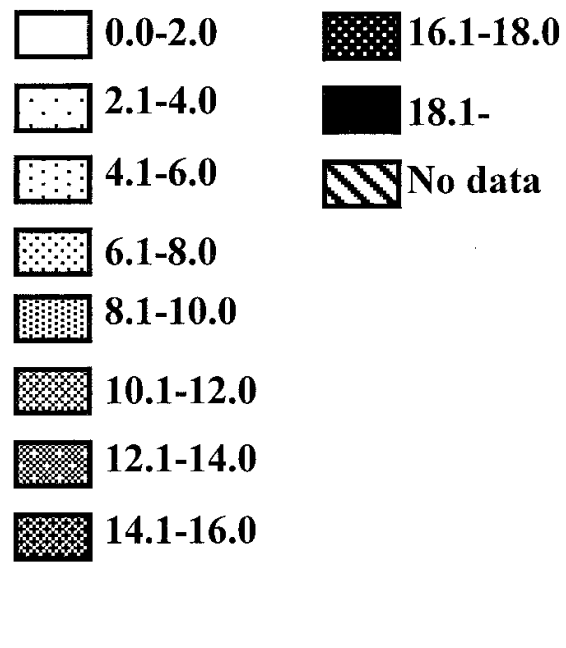

Fig. 3. Spatial distribution of airborne ascospore concentrations (AAC) of Venturia inaequalis on 5, 8, 24, and 26 May and 6 June measured in a commercial apple orchard in 1999. 
mined by the $\chi^{2}$ test, the spatial distribution was considered to be random. Furthermore, the negative binomial probability distribution was used to test a departure from randomness or aggregation $(11,32)$.

Geostatistical analysis. Semivariogram (also called variogram) analysis was performed on the PAD and AAC using the Cokriging Software version $1.0 \mathrm{~b}$ for spatial interpolation of agroclimatic data (10). The semivariogram is a mathematical function defined as half the average of the square differences in values between pairs of samples separated by a given distance $(h)$ and which characterizes the dependence between variables (PAD or AAC) at different points in space $(10,13)$. Semivariances $\gamma(h)$ were calculated for lag distances $(h)$ of 5 to $50 \mathrm{~m}$ and of 3.5 to $35 \mathrm{~m}$ between paired quadrats in the orchard block, for all cultivars and only McIntosh, respectively (10).

Each semivariogram was constructed by plotting the semivariance as a function of the lag distance. Spatially dependent samples express a semivariance that starts out small and increases with in- creasing lag distance (19). The range of spatial dependence is the lag distance at which the semivariance approaches a constant value, and indicates the distance where the sample values are no longer correlated with each other (14). Samples located at distances greater than the range of spatial dependence are not spatially dependent, whereas those separated at distances smaller than the range are spatially correlated. The sill is a constant value where the semivariance levels off. The sill generally approximates the sample semivariance. The point at which the semivariance crosses the $y$ axis (nugget variance) represents the spatial variation occurring below the minimum lag distance and measurement error causing discontinuity in the semivariogram at lag zero (14).

Linear and nonlinear models were fit to the semivariograms to describe the relationship between the semivariance and the lag distance $(h)$. The nugget, the sill, and the range parameters were derived from the adjusted model (14). Linear, quadratic, exponential, spherical, rational quadratic, Gaussian, power, and wave models (11) were fitted to the semivariograms using Marquardt

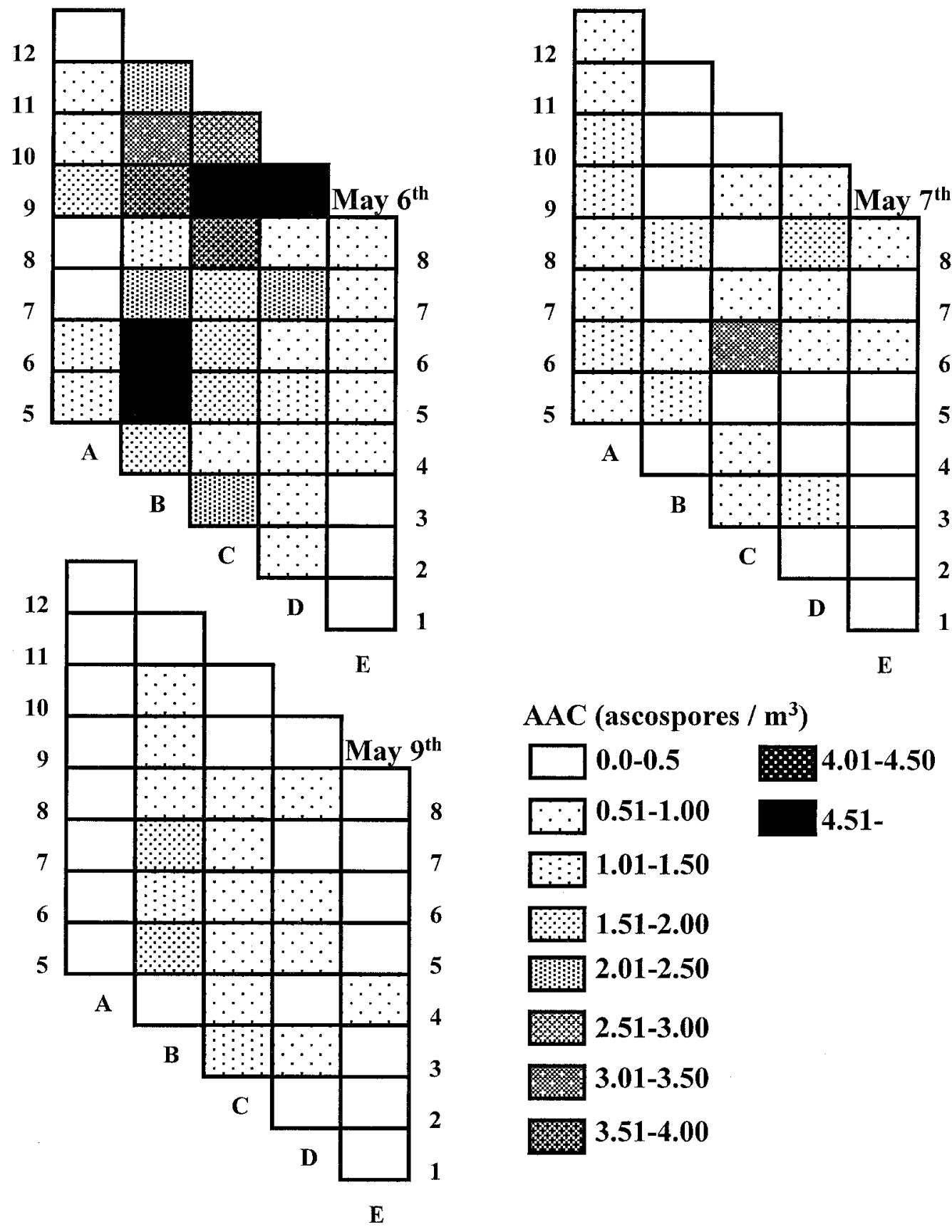

Fig. 4. Spatial distribution of airborne ascospore concentrations (AAC) of Venturia inaequalis on 6, 7, and 9 May measured in a commercial apple orchard in 2000. 
iterative method technique of the nonlinear regression (NLIN) procedure of Statistical Analysis System (Windows version 6.12; SAS Institute, Inc., Cary, NC). The fit of the models to the semivariograms was evaluated based on the coefficients of determination, the sum of squares, and the asymptotic standard error of the estimation (23). Model parameters, including nugget variance, range of spatial dependence, and sill, were used to characterize the semivariograms.

The Spearman correlation coefficient between the PAD and the AAC was calculated for each separate AAC sampling date and the total airborne ascospore ejection of 1999 and 2000, summation of the values of AAC within each quadrat over the eight ejection dates.

\section{RESULTS}

Mapping. PAD maps were drawn with 10 concentration classes that ranged from 0 to 16,000 ascospores per $\mathrm{m}^{2}$ (Fig. 2). The quadrats in rows $\mathrm{A}$ and $\mathrm{E}$ were composed of cvs. Red Delicious and
Lobo, respectively, and had much lower inoculum levels in both 1999 and 2000 (Fig. 2, Table 1). These two cultivars also had lower levels of scab infection at the time of the fall scab assessment. The three rows of quadrats in the middle of the orchard block (rows B, C, and D) all consisted of McIntosh, and had a higher disease severity, raising the value of the PAD in those quadrats. AACs measured on 5, 8, 24, and 26 May and 6 June 1999 and 6, 7, and 9 May 2000 are presented in gray-tone maps of the 40 quadrats (Figs. 3 and 4). The AAC ranged from 0 to 20 ascospores per $\mathrm{m}^{3}$, which was divided into 10 classes of 2 ascospores per $\mathrm{m}^{3}$ of air. To facilitate comparison, the same scale of the AAC was used for all ejection events within the same year. Overall, the samplers placed in quadrats of rows B, C, and $\mathrm{D}$, those consisting of McIntosh trees, captured more ascospores than those placed in other quadrats (Table 1). In 1999, average AAC was 5.4, 8.8, 4.7, 1.7, and 2.7 ascospores per $\mathrm{m}^{3}$ across all quadrats on 5, 8, 24, and 26 May and 6 June, respectively. The highest average AAC and highest AAC measured in a quadrat (18.5 ascospores per $\mathrm{m}^{3}$ in quadrat C7) occurred on 8 May 1999

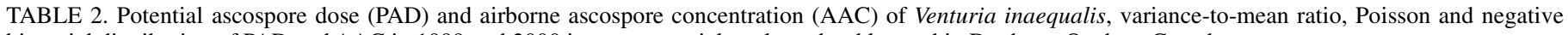
binomial distribution of PAD and AAC in 1999 and 2000 in a commercial apple orchard located in Dunham, Quebec, Canada

\begin{tabular}{|c|c|c|c|c|c|}
\hline \multirow[b]{2}{*}{ Sampling date } & \multirow[b]{2}{*}{ Year } & \multirow[b]{2}{*}{ Average PAD/AAC ${ }^{a}$} & \multirow[b]{2}{*}{ Variance-to-mean ratio ${ }^{b}$} & \multicolumn{2}{|c|}{$\chi^{2} P$ value } \\
\hline & & & & Poisson $^{c}$ & Negative binomial $^{\mathrm{d}}$ \\
\hline PAD & 1999 & 5,211 & 4,850 & $1.19 \times 10^{-150}$ & $4.64 \times 10^{-13}$ \\
\hline PAD & 2000 & 5,762 & 2,432 & $3.62 \times 10^{-50}$ & $4.30 \times 10^{-3}$ \\
\hline \multicolumn{6}{|l|}{ AAC } \\
\hline May 5 & 1999 & 5.3 & 3.2 & $3.37 \times 10^{-20}$ & 0.197 \\
\hline May 8 & 1999 & 9.0 & 2.0 & $3.23 \times 10^{-15}$ & 0.275 \\
\hline May 24 & 1999 & 4.7 & 2.1 & $1.66 \times 10^{-3}$ & 0.847 \\
\hline May 26 & 1999 & 1.7 & 0.3 & $3.32 \times 10^{-8}$ & 0.972 \\
\hline June 6 & 1999 & 2.7 & 0.8 & $6.62 \times 10^{-1}$ & 0.997 \\
\hline May 6 & 2000 & 1.8 & 1.65 & $1.78 \times 10^{-9}$ & $3.48 \times 10^{-2}$ \\
\hline May 7 & 2000 & 0.6 & 0.55 & $1.49 \times 10^{-1}$ & 0.999 \\
\hline May 9 & 2000 & 0.5 & 0.32 & $7.86 \times 10^{-1}$ & $\ldots$ \\
\hline
\end{tabular}

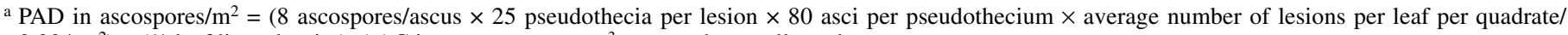
$\left.0.004 \mathrm{~m}^{2}\right) \times(\%$ leaf litter density $)$. AAC in ascospores per $\mathrm{m}^{3}$ averaged over all quadrats.

b Variance to mean ratio $=s^{2} / \bar{x}$, where $s^{2}=$ sample variance and $\bar{x}=$ sample mean.

c The Poisson distribution was calculated using $P(x)=\frac{e^{-\mu} \mu^{x}}{x !}, x=0,1,2, \ldots$, where $\mu$ represents the population mean and $x$ represents the class of PAD or AAC.

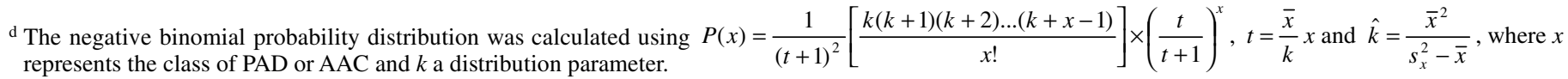

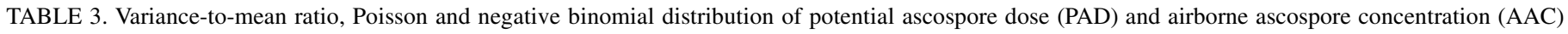
of Venturia inaequalis for cv. McIntosh in 1999 and 2000 in a commercial apple orchard located in Dunham, Quebec, Canada

\begin{tabular}{|c|c|c|c|c|}
\hline \multirow[b]{2}{*}{ Sampling date } & \multirow[b]{2}{*}{ Year } & \multirow[b]{2}{*}{ Variance to-mean ratio ${ }^{a}$} & \multicolumn{2}{|c|}{$\chi^{2} P$ value } \\
\hline & & & Poisson $^{b}$ & Negative binomial $^{\mathrm{c}}$ \\
\hline $\mathrm{PAD}^{\mathrm{d}}$ & 1999 & $1,793.6$ & 0.108 & 0.786 \\
\hline PAD & 2000 & 880.2 & 0.876 & 0.294 \\
\hline \multicolumn{5}{|l|}{$\mathrm{AAC}^{\mathrm{e}}$} \\
\hline May 5 & 1999 & 1.8 & 0.029 & 0.617 \\
\hline May 8 & 1999 & 1.5 & 0.229 & 0.610 \\
\hline May 24 & 1999 & 1.1 & 0.657 & 0.974 \\
\hline May 26 & 1999 & 0.3 & $1.078 \times 10^{-8}$ & 0.967 \\
\hline June 6 & 1999 & 0.7 & 0.669 & 0.744 \\
\hline May 6 & 2000 & 1.4 & 0.026 & 0.791 \\
\hline May 7 & 2000 & 0.7 & 0.721 & 1.000 \\
\hline May 9 & 2000 & 0.2 & 0.205 & $\ldots$ \\
\hline
\end{tabular}

a Variance to mean ratio $=s^{2} / \bar{x}$, where $s^{2}=$ sample variance and $\bar{x}=$ sample mean.

b The Poisson distribution was calculated using $P(x)=\frac{e^{-\mu} \mu^{x}}{x !}, x=0,1,2, \ldots$, where $\mu$ represents the population mean and $x$ represents the class of PAD or AAC.

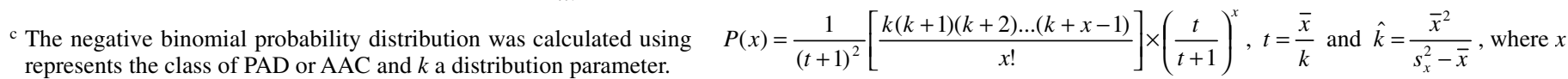

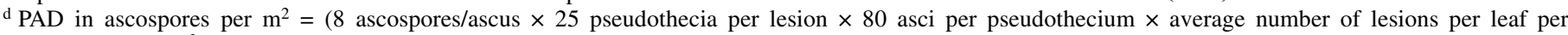
quadrate $\left./ 0.004 \mathrm{~m}^{2}\right) \times(\%$ leaf litter density $)$.

e AAC in ascospores per $\mathrm{m}^{3}$ averaged over all quadrats. 
(Fig. 3). Overall in 2000, lower AAC were measured, with averages of 1.8, 0.6, and 0.5 ascospores per $\mathrm{m}^{3}$ (Fig. 4). In both years, when considering the cultivars separately, the lowest PAD and AAC were observed for Red Delicious, followed by Lobo and McIntosh (Table 1).

Distribution analysis. The variance to mean ratio of the PAD of 1999 and 2000 and the AAC of 5, 8, and 24 May 1999 and 6 May 2000 were $>1$ (Table 2), suggesting an aggregated pattern of distribution. The variance to mean ratios of the AAC of 26 May and 6 June 1999 and 7 and 9 May 2000 were <1, indicating a regular pattern of distribution (Table 2). The AAC measured on these dates were lower than those for the other sampling dates.

The frequencies of the different classes of PAD and AAC did not follow the Poisson pattern of distribution $(P<0.01)$, except the AAC of 6 June 1999 and 7 and 9 May $2000(P>0.01)$ as tested by $\chi^{2}$ (Table 2). This indicates that the PAD and the AAC of 5, 8, 24, and 26 May 1999 were not randomly distributed within the orchard block. On 6 June 1999 and 7 and 9 May 2000, the AAC was low and the spatial distribution was random according to the Poisson distribution. The classes of the PAD did not follow the negative binomial probability distribution $(P<0.01)$, indicating that the data were not aggregated (Table 2). For all AAC measurement dates, except 9 May 2000, the classes followed the negative binomial distribution $(P>0.01)$, thereby confirming an aggregated pattern of spatial distribution. Distribution analysis conducted on the PAD and AAC for cv. McIntosh only revealed a similar pattern of distribution. The variance to mean ratios of the PAD of 1999 and 2000 and the AAC of 5, 8, and 24 May 1999 and 6 May 2000 were $>1$, indicating that the pattern of distribution was aggregated (Table 3). For the other AAC, the variance-tomean ratios were $<1$, suggesting a regular pattern of distribution (Table 3). With the exception of 26 May, the frequencies of the different classes of PAD and AAC did follow the Poisson distribution $(P>0.01)$ (Table 3$)$, indicating that the PAD and the AAC were randomly distributed within the McIntosh block (Table 3). Similarly, for both PAD and AAC, the classes followed the negative binomial distribution $(P>0.01)$, suggesting that the pattern of spatial distribution among the quadrats with cv. McIntosh was aggregated.

Geostatistical analysis. Spatial dependence was observed, and it was possible to describe the semivariograms using all models (linear, quadratic, exponential, spherical, rational quadratic, Gaussian, power, and wave) (data not shown). The spherical model provided the best fit for most of the semivariograms describing PAD and AAC in both 1999 and 2000, with $R^{2}$ ranging from 0.58 to 0.91 (Table 4; Figs. 5 and 6). Overall, the dependence between the PAD values decreased with increasing distance between quadrats, and nugget variance ( $y$ intercept) value was small relative to the total variance in both 1999 and 2000 (Figs. 5 and 6). This indicates a strongly spatially dependent structure and spatial distribution explaining a large proportion of the variation (23). The shape of the semivariogram for the AAC on 5 May 1999 was very similar to the one for the PAD, indicating similar cluster groupings in the field (Fig. 5). The periodicity observed reflected fluctuations in AAC correlations among quadrats and was probably due to the presence of multiple aggregations in the orchard. The range of spatial dependence was $34.9 \mathrm{~m}$ with a sill 1.36, creating a relatively steep slope revealing a strong spatial dependence. Periodicity in the data of the semivariogram of 24 May 1999 (Fig. 5) reflected the fluctuation in the dependence of AAC over the quadrats. Quadrats separated by distance greater than $36 \mathrm{~m}$ (range $a$ ) are not spatially dependent (35). On 26 May 1999 (Fig. 5), no strong spatial dependence was detected over the quadrats. Periodic variation of semivariance was observed. None of the models tested fit the semivariogram curve. On 6 June 2000 (Fig. 6 ), the semivariogram showed a particular pattern where the semivariance over quadrats separated by $36 \mathrm{~m}$ was much smaller than the semivariance at lag distances slightly shorter or longer than $36 \mathrm{~m}$. The linear model had the best fit $\left(R^{3}=0.66\right)$, with a slope (b) of 0.03. In 2000, the spherical model best fitted the three AAC sampling dates. On 7 May, the coefficient of regression was relatively low (0.58) because of the lower semivariance between lag distances of 40 to $50 \mathrm{~m}$. The relatively flat shape of the spherical curve indicates a weak spatial dependence between quadrats. When the analysis was conducted with the data for cv. McIntosh only, spatial dependence was observed, and it was possible to describe the semivariograms using the wave or the quadratic model. Overall, the $R^{2}$ values were lower than for the analysis with data from all three cultivars. The wave model provided the best fit for the semivariograms that described the PAD in both 1999 and 2000 with $R^{2}$ of 0.40 and 0.67 , respectively. The shape of the semivariogram for the AAC on 8 and 26 May 1999 and 6 May 2000 was very similar, and the best fit also was provided with the wave model with $R^{2}$ of $0.32,0.42$, and 0.20 , respectively. This indicated that for the PAD in both 1999 and 2000 and AAC on 5 and 26 May 1999 and 6 May 2000 showed some sort of periodicity in the spatial pattern. The quadratic model provided the best fit for the

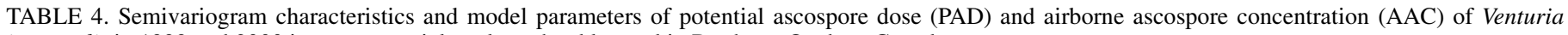
inaequalis in 1999 and 2000 in a commercial apple orchard located in Dunham, Quebec, Canada

\begin{tabular}{|c|c|c|c|c|c|c|c|}
\hline Data $^{a}$ & Year & Model $^{\mathrm{b}}$ & $R^{2}$ & Nugget variance $^{\mathrm{c}}\left(c_{0}\right)$ & $c_{1}$ or $b^{\mathrm{d}}$ & $a^{\mathrm{e}}$ & Sill $^{\mathrm{f}}$ \\
\hline PAD & 1999 & Spherical & 0.73 & $0.13(0.000)$ & $1.23(0.102)$ & $41.7(6.145)$ & 1.35 \\
\hline PAD & 2000 & Spherical & 0.81 & $0.07(0.000)$ & $1.17(0.090)$ & $43.9(6.130)$ & 1.24 \\
\hline \multicolumn{8}{|l|}{ AAC } \\
\hline May 5 & 1999 & Spherical & 0.63 & $-0.04(0.358)$ & $1.39(0.446)$ & $34.9(3.106)$ & 1.36 \\
\hline May 8 & 1999 & Spherical & 0.90 & $0.07(0.000)$ & $1.26(0.047)$ & $38.8(2.237)$ & 1.33 \\
\hline May 24 & 1999 & Spherical & 0.68 & $0.00(0.000)$ & $1.33(0.091)$ & $36.1(3.197)$ & 1.33 \\
\hline May 26 & 1999 & $\ldots$ & $\ldots$ & $\ldots$ & 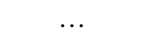 & $\ldots$ & $\ldots$ \\
\hline June 6 & 1999 & Linear & 0.66 & $0.33(0.215)$ & $0.03(0.007)$ & $\ldots$ & $\ldots$ \\
\hline May 6 & 2000 & Spherical & 0.91 & $0.33(0.000)$ & $1.09(0.127)$ & $53.07(9.716)$ & 1.42 \\
\hline May 7 & 2000 & Spherical & 0.58 & $0.92(0.000)$ & $6.29(0.058)$ & $25.65(1.268)$ & 7.21 \\
\hline May 9 & 2000 & Spherical & 0.87 & $0.42(0.000)$ & $0.93(0.092)$ & $48.63(8.325)$ & 1.35 \\
\hline
\end{tabular}

a PAD and AAC measured on the five dates between 5 May and 6 June.

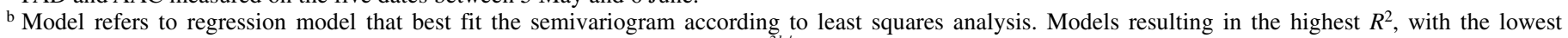
mean square error, indicated best fit. Spherical model: $\gamma(h)=c_{0}+c_{1}\left(1-e^{-3 h / a}\right)$ and linear model $\gamma(h)=c_{0}+b \times h$. Degree of freedom of the model was equal to 8 .

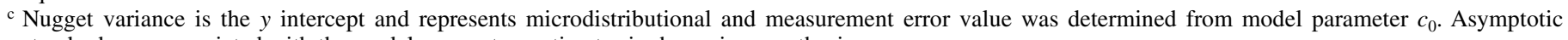
standard error associated with the model parameters estimates is shown in parenthesis.

d Values that represented model parameters for structural variance $c_{1}\left(c_{0}+c_{1}=\right.$ sill) for nonlinear models or slope $b$ for linear model.

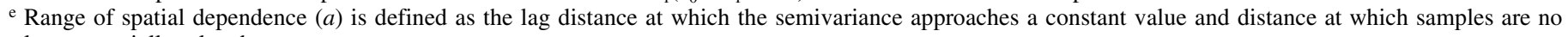
longer spatially related.

f Sill defined as semivariance value beyond range of spatial dependence. 
AAC on 5 and 24 May 1999, 6 June 1999, and 9 May 2000 with $R^{2}$ of $0.65,0.72,0.60$, and 0.50 , respectively. This indicated that there was a positive correlation at short lag distances. On 7 May 2000 , the best fit was obtained with the exponential model $\left(R^{2}=0.24\right)$.

No correlations were observed between the PAD and individual AAC sampling dates except for 8 May $1999(r=0.48$ and $P=$ $0.002)$. However, significant positive correlation $(r=0.78$ and $P<$ 0.0001 ) was obtained between the PAD and total AAC of 1999 but not in 2000 (data not shown). Total AAC is the summation of the values of each of the five sampling dates of AAC. When consider- ing cv. McIntosh only, significant positive correlation was obtained only between the PAD and AAC of 6 June $1999(r=0.70$ and $P=0.0351)$ and of 6 May $2000(r=0.78$ and $P=0.0129)$.

\section{DISCUSSION}

To our knowledge, this is the first study of the distribution pattern of airborne ascospores of $V$. inaequalis in a commercial apple orchard. The results clearly demonstrate that the AAC was not uniformly distributed in this 0.43 -ha commercial apple orchard. Even if each ejection event had a different AAC, similar
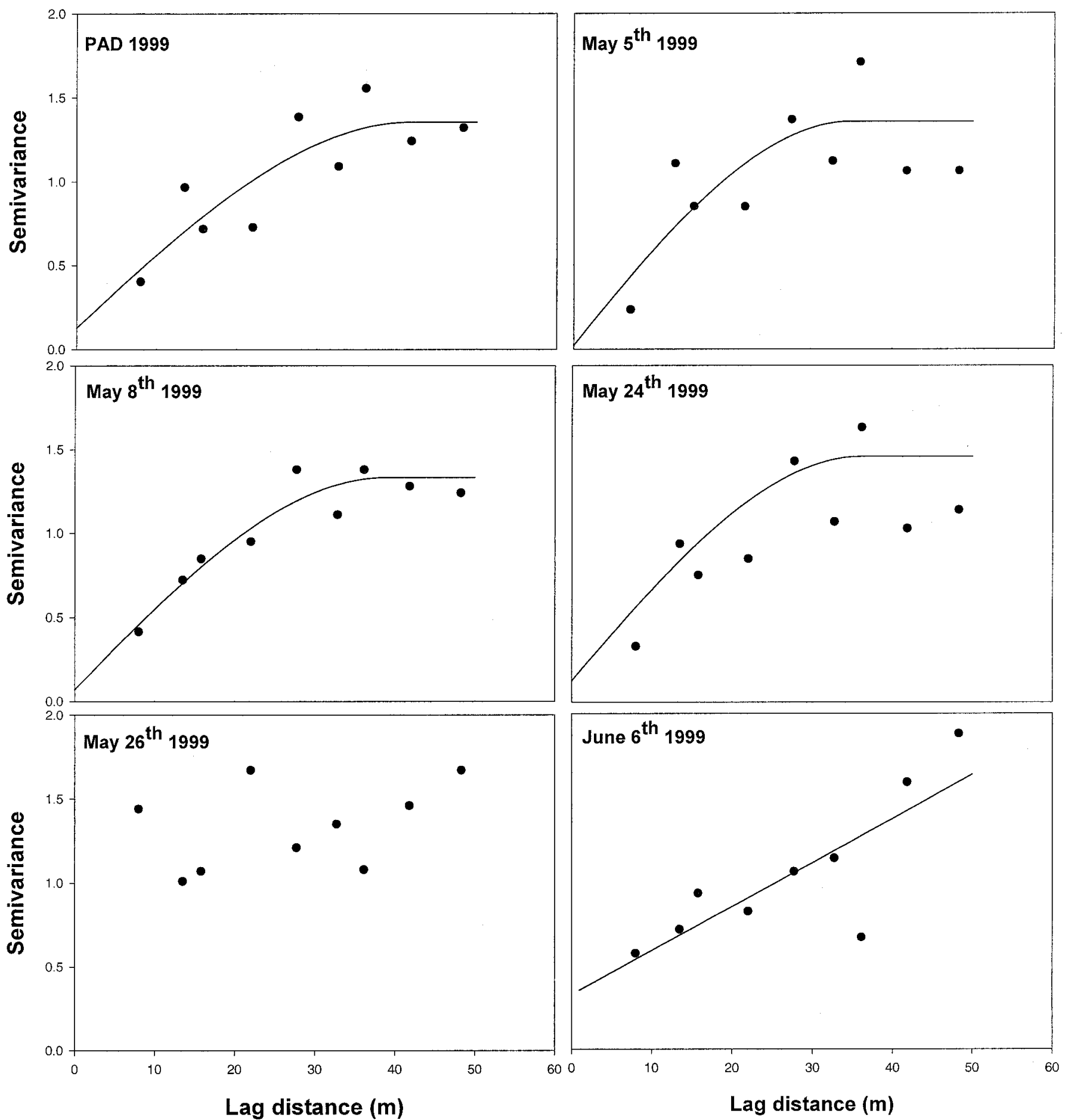

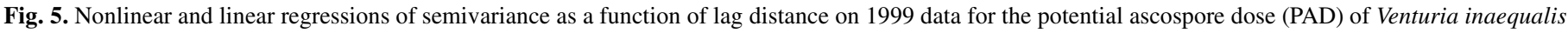

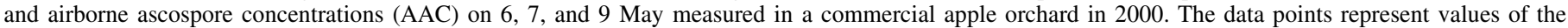
semivariance and the line represents the regression calculated based on equations presented in Table 4. 
patterns of distribution were observed for most of them in both mixed- and single-cultivar blocks.

Spatial distribution of the primary inoculum of $V$. inaequalis was studied by the assessment of the PAD and the AAC in 1999 and 2000. The results of the present study may not apply to all orchards because the spatial pattern of distribution of ascospore is influenced by numerous factors (5), which include the amount of overwintering inoculum, the size of tree, tree spacing, wind velocity, and rate of leaf decomposition. However, it provides a good estimation of the spatial distribution of ascospores of $V$. inaequalis. The orchard block was divided into 40 quadrats to give the smallest sampling units technically reasonable with spore samplers. The spring of 1999 was relatively early and dry but there was a sufficient number of rain events to collect data during the major ascospore ejections. In 2000, the spring was wet and not favorable for concentrated ascospore ejection. The numerous rain events constantly depleted the stock of mature ascospores without accumulating enough degree days to allow a large quantity of ascospore to mature between two ejection events.

The large variation in disease severity among the quadrats was responsible for the large variance of the PAD observed. For example, in 1999, the lowest and highest values for the PAD were 49 and 17,893 ascospores per $\mathrm{m}^{2}$, respectively. This explains why the variance-to-mean ratio was so high for the PAD. Quadrats located in rows (A and E) composed of cultivars that are less susceptible than McIntosh had PAD values smaller than the others rows, thereby explaining part of the variation and the nonrandom pattern of distribution. However, when data were analyzed for $\mathrm{cv}$.
McIntosh only, the PAD and AAC had a random or aggregated pattern of distribution, which indicated that not only cultivar influenced the pattern of distribution. This particular phenomenon could not be observed on the semivariogram because the lag distance of $50 \mathrm{~m}$ was too short to show the spatial dependence of the quadrats on opposite sides of the orchard block.

Overall, AAC observed in all quadrats or only in quadrats with cv. McIntosh were aggregated. The variance-to-mean ratio of 26 May and 6 June 1999 and 7 and 9 May 2000 indicated a regular pattern of distribution, possibly because of the relatively low average AAC measured. AACs in all quadrats on 26 May 1999 and 7 and 9 May 2000 were represented by only one or two classes of concentration. The spherical model fit most of the semivariograms, indicating that the semivariance increased with the distance between quadrat locations and reached a plateau at a given distance or sill. This confirms the spatial aggregation pattern of the ascospore concentrations (19). On 26 May 1999, the AAC measured was very low and close to the detection threshold of the sampler (3). This may explain why there was no spatial dependence observed among the quadrats. On 6 June 1999, the semivariogram presented a particularly strong dependence among quadrats separated by approximately $36 \mathrm{~m}$. The five quadrats with the highest AACs (B7, C10, D5, D8, and E8) were separated by an average distance of $35 \mathrm{~m}$, increasing the spatial dependence at this particular lag distance. The particular localization of these four quadrats may explain the particular shape of the semivariogram. On 7 May 2000, only one quadrat had a concentration greater than 3 ascospores per $\mathrm{m}^{2}$. This quadrat (C6) was located in
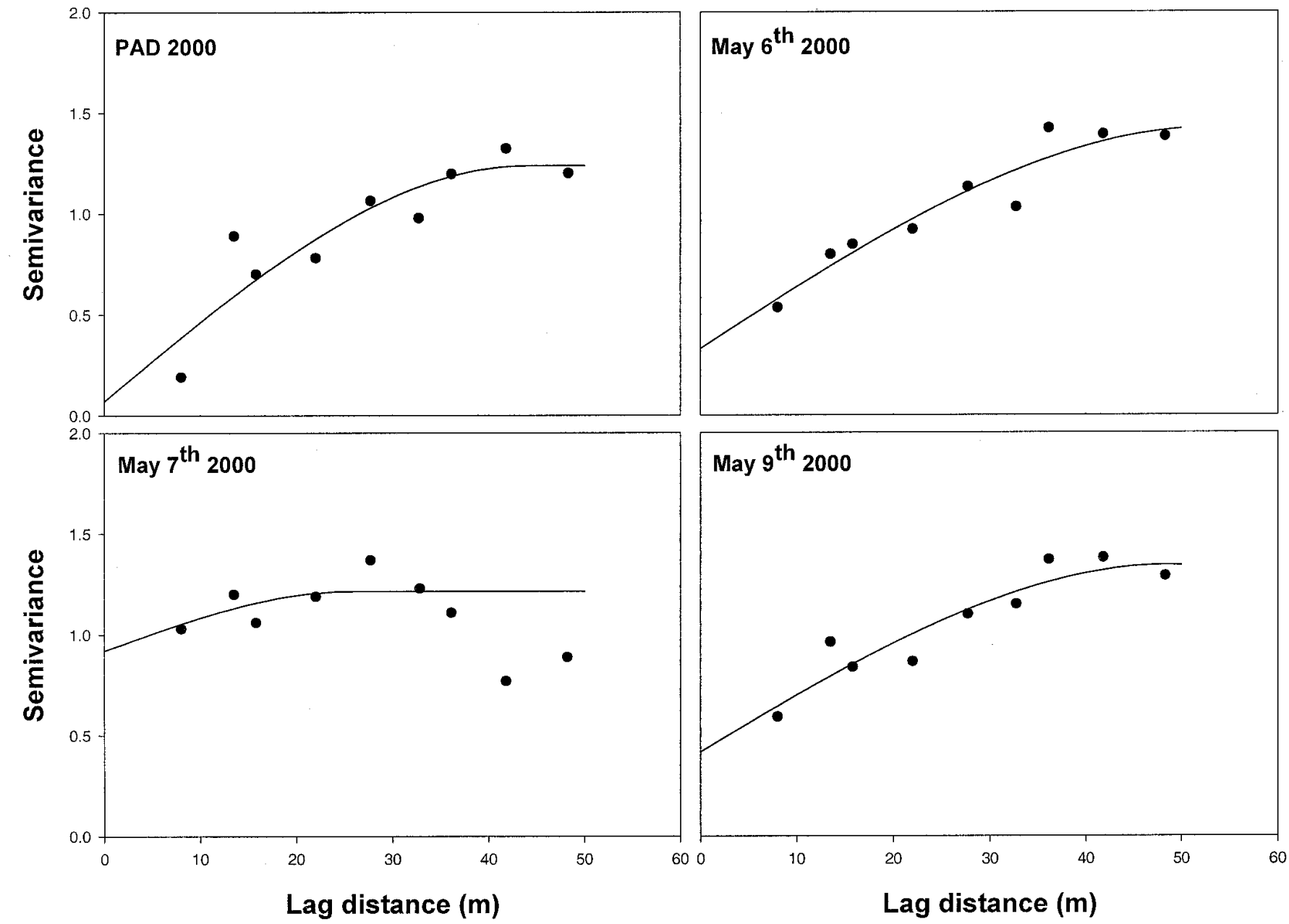

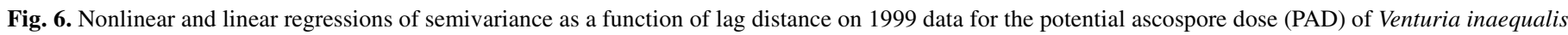

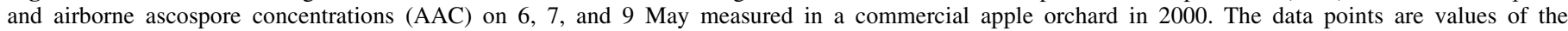
semivariance and the line represents the regression calculated based on equations presented in Table 4 . 
the middle of the orchard; therefore, the level of spatial dependence between $\mathrm{C} 6$ and the other quadrat is lower than the other combinations of quadrat. This situation is observed in Figure 6, where the semivariance is low at a lag distance of about $40 \mathrm{~m}$, indicating that the level of spatial dependence between C6 and the edge of the orchard is lower. The analysis conducted with the data from cv. McIntosh only revealed a different pattern of distribution of PAD and AAC than for data from all cultivars. More periodicity was observed in the distribution of PAD and AAC from McIntosh quadrats, but this was based on a reduced number of quadrats. Nevertheless, all tests indicated that the PAD and AAC were not uniformly distributed in the mixed or single cultivar block. Similar statistical analyses were done in other studies on spatial distribution $(17,23,29,31,34,35)$. Even if these studies were not done with airborne spore concentrations, semivariograms were used in geostatistical analyses to indicate the dependence of spatial data in plant pathology.

The absence of uniformity in the AAC spatial dispersion potentially could be explained by a nonuniform pattern of dispersion of the overwintering inoculum on the ground and a limited distance of spore movement reducing the mixing of the AAC caused by air currents. Apple scab is a polycyclic disease, and the infection foci, originating from the primary inoculum, are accentuated by the secondary disease cycles. The spatial dispersion of the secondary inoculum is very limited because conidia are mainly splash dispersed within the same tree $(22,24)$. These infection foci could be responsible for the nonuniform pattern of disease severity in the orchard. At leaf fall, the scabbed leaves are scattered by the wind but are not sufficiently randomly mixed to homogenize the infection foci of infected leaves. Longer grass cover in the rows may contribute to catching and limiting scatter distance of the leaves in the autumn. Common and abundant rainfall at this period of the year also may reduce leaf movement because wet leaves are less likely to be scattered by wind. After the snow has melted, the leaves are firmly attached to the ground, and leaf decomposition may vary depending on localized microclimate. This also may contribute to the aggregated pattern of ascospore ejections.

The PAD is an estimation of the total number of ascospores that could potentially be released per square meter during the entire primary scab season. This single value, representing the whole season, may explain why the PAD was only correlated with the total amount of AAC and with the highest AAC measured on (8 May 1999). The correlation between the PAD and the AAC suggests that scabbed leaves are deposited at a short distance from the trees where the PAD was measured and that these spore samplers have a short radius of action. In an attempt to limit the number of spore samplers used to estimate the AAC under commercial conditions, the samplers should be located where the chance of measuring a relatively high $\mathrm{AAC}$, in comparison with other areas, is maximized; for instance, where scab level is high and leaf litter dense. This would allow the grower using a conservative management regime to minimize the risk of using the AAC as an apple scab management tool. A small-scale PAD measurement then could be used as an estimate of the spatial distribution of ascospores and help to decide the location where the spore samplers should be placed to avoid an underestimation of the AAC.

One of the main difficulties in managing apple scab, especially under reduced fungicide programs, is to estimate the risk of scab infection. For primary infections, this risk depends on the number of ascospores available (6), on infection conditions mainly, leaf wetness duration and temperature (27), and the amount of susceptible tissues (8). As opposed to weather, information on leaf expansion and the amount of AAC is not available. There are few models available to estimate the probability of primary scab infection (8). However, these models generally are too sophisticated to be used directly by growers. The spore sampler offers several advantages because they are easy to use, require limited equipment, and are inexpensive. Despite these advantages, much more information on reliability of spore samplers will be required before they can be used to time fungicide applications.

In most management programs, it is assumed that the main source of ascospores is the apple leaf litter within the orchard. This assumption is supported by a recent study by Hsiang et al. (18) who demonstrated, using random amplified polymorphic DNA analysis, that the ascospores of $V$. inaequalis have an effective dispersal radius of $20 \mathrm{~m}$.

Kaplan (21) conducted a detailed study on the dispersal of ascospores of $V$. inaequalis and showed that there was a steep ascospore dispersal gradient near the source. In this study, ascospores were trapped at $0.5 \mathrm{~m}$ above the source and within the canopy of four apple trees at $5.4 \mathrm{~m}$ from the source. The same author (21) determined that, at 5 to $6 \mathrm{~m}$ from the source, AAC was reduced by $99 \%$. In our study, spore samplers located higher above the ground probably would have measured a more uniform AAC because of the additional air mixing (5). However, the ascospore concentration would have been significantly lower, even to the point of nondetection $(3,5)$.

In order to use spore trapping as a real-time inoculum assessment tool, greater knowledge on the uniformity of the ascospore distribution was required. According to the results of this study, ascospores of $V$. inaequalis were not uniformly distributed but distinctly aggregated for the main ascospore ejection events observed. Therefore, more than one sampler probably would be required to be representative of the AAC over the orchard. However, increasing the number of samplers might not be practical for growers. The possibility of monitoring ascospore concentration from a sample of leaves collected and overwintered in a given orchard block should be investigated. This approach would have the advantage of improving detection of low amount of ascospores by using a higher amount of leaves per square meter or using only scabbed leaves, without increasing the number of samplers. This way, spore samplers may be used in conjunction to the weatherbased infection models to improve scab management.

\section{ACKNOWLEDGMENTS}

We thank the Conseil de la Recherche en Pêche et en Alimentation du Québec (CORPAQ) for financial support, and P. Dutilleuil and W. W. Turechek for their help in the statistical analysis.

\section{LITERATURE CITED}

1. Aylor, D. 1989. Aerial spore dispersal close to a focus of disease. Agric. For. Meteorol. 47:109-122.

2. Aylor, D. 1990. The role of intermittent wind in the dispersal of fungal pathogens. Annu. Rev. Phytopathol. 28:73-92.

3. Aylor, D. E. 1993. Relative collection efficiency of Rotorod and Burkard spore samplers for airborne Venturia inaequalis ascospores. Phytopathology 83:1116-1119.

4. Aylor, D. E. 1994. Role of turbulence in escape of Venturia inaequalis ascospores from a grass canopy. Pages 397-400 in: Conf. Proc. Am. Meteorol. Soc., Boston, MA.

5. Aylor, D. E. 1995. Vertical variation of aerial concentration of Venturia inaequalis ascospores in an apple orchard. Phytopathology 85:175-181.

6. Aylor, D. E. 1998. The aerobiology of apple scab. Plant Dis. 82:838-849.

7. Aylor, D. E., and Anagnostakis, S. L. 1991. Active discharge distance of ascospores of Venturia inaequalis. Phytopathology 81:548-551.

8. Aylor, D. E., and Kiyomoto, R. K. 1993. Relationship between aerial concentration of Venturia inaequalis ascospores and development of apple scab. Agric. For. Meteorol. 63:133-147.

9. Aylor, D., and Sutton, T. 1992. Release of Venturia inaequalis ascospores during unsteady rain: Relationship to spore transport and deposition. Phytopathology 82:532-540.

10. Bogaert, P., Mahau, P., and Beckers, F. 1995. The spatial interpolation of agro-climatic data. Cokrigg Software and Source code. Faculté des sciences agronomiques, Université Catholique de Louvain, Louvain-laNeuve, Belgium.

11. Campbell, C. L., and Madden, L. V. 1990. Introduction to Plant Disease Epidemiology. John Wiley \& Sons, Toronto. 
12. Carisse, O., Philion, V., Rolland, D., and Bernier, J. 2000. Effect of fall application of fungal antagonists on spring ascospore production of apple scab pathogen, Venturia inaequalis. Phytopathology 90:31-37.

13. Cressie, N. 1985. Fitting variogram models by weighted least squares. Math. Geol. 17:405-421.

14. Francl, L. J., and Neher, D. A. 1997. Exercises in Plant Disease Epidemiology. The American Phytopathological Society, St. Paul, MN.

15. Gadoury, D. M., and MacHardy, W. E. 1982. A model to estimate the maturity of ascospores of Venturia inaequalis. Phytopathology 72:901904.

16. Gadoury, D. M., and MacHardy, W. E. 1986. Forecasting ascospore dose of Venturia inaequalis in commercial apple orchards. Phytopathology 76:112-118.

17. Gottwald, T. R., Camba, M., Moreno, P., Camarasa, E., and Piquer, J. 1996. Spatial and temporal analyses of citrus tristeza virus in eastern Spain. Phytopathology 86:45-55.

18. Hsiang, T., Ma, X. L., and Zhou, T. 2000. Temporal and spatial analyses of genetic diversity in Venturia inaequalis assessed by RAPD markers. Can. J. Plant Pathol. 22:186.

19. Isaaks, E. H., and Srivastava, R. M. 1989. Applied Geostatistics. Oxford University Press, Oxford.

20. Jones, A. L., and Aldwinckle, H. S. 1990. Compendium of Apple and Pear Diseases. The American Phytopathological Society, St. Paul, MN.

21. Kaplan, J. D. 1986. Dispersal gradients and deposition efficiency of Venturia inaequalis ascospores and their relationship to lesion densities. $\mathrm{Ph}$.D. thesis. University of New Hampshire, Durham.

22. Keitt, G. W., and Jones, A. K. 1926. Studies of the epidemiology and control of apple scab. Wis. Agric. Exp. Stn. Bull. 73:1-194.

23. Larkin, R. P., Gumpertz, M. L., and Ristaino, J. B. 1995. Geostatistical analysis of Phytophthora epidemic development in commercial bell pepper fields. Phytopathology 85:191-203.

24. MacHardy, W. E. 1996. Apple Scab: Biology, Epidemiology, and
Management. The American Phytopathological Society, St. Paul, MN

25. MacHardy, W. E. 1999. A review of apple scab research presented at the IOBC Integrated Control of Pome Fruit Diseases workshops, 1987-1999. IOBC/WPRS Bull. 23:56

26. MacHardy, W. E., Gadoury, D. M., and Rosenberger, D. A. 1993. Delaying the onset of fungicide programs for control of apple scab in orchards with low potential ascospore dose of Venturia inaequalis. Plant Dis. 77:372-375.

27. Mills, W. D. 1944. Efficient use of sulfur dusts and sprays during rain to control apple scab. Cornell Ext. Bull. 630:1-4.

28. Mueller-Dombois, D., and Ellenberg, H. 1974. Aims and Methods of Vegetation Ecology. John Wiley \& Sons, New York.

29. Munkvold, G. P., Duthie, J. A., and Marois, J. J. 1993. Spatial patterns of grapevines with Eutypa dieback in vineyards with or without perithecia. Phytopathology 83:1440-1448.

30. Philion, V., Carisse, O., Garcin, A., and Vanesson, S. 1997. Monitoring airborne ascospore of Venturia inaequalis in the control of apple scab. IOBC/WPRS Bull. 20:180-184.

31. Savary, S., Castilla, N. P., and Willocquet, L. 2001. Analysis of the spatiotemporal structure of rice sheath blight in a farmer's field. Plant Pathol. 50:53-68.

32. Scherrer, B. 1984. Biostatistique. Gaëtan Morin. Boucherville, Québec, Canada.

33. St-Arnaud, M., and Neumann, P. 1990. Évaluation au Québec d'un modèle de prédiction de la fin de la période annuelle d'éjection des ascospores du Venturia inaequalis. Phytoprotection 71:17-23.

34. Wu, B. M., van Bruggen, A. H. C., Subbarao, K. V., and Pennings, G. G. H. 2001. Spatial analysis of lettuce downy mildew using geostastistics and geographic information systems. Phytopathology 91:134-142.

35. Xiao, C. L., Hao, J. J., and Subbarao, K. V. 1997. Spatial pattern of microsclerotia of Verticillium dahliae in soil and Verticillium wilt of cauliflower. Phytopathology 87:325-331. 